\title{
Deliverability of wells in carbonate gas condensate reservoirs and the capillary number effect
}

\author{
Li Yong, Hu Yongle*, Li Baozhu and Xia Jing \\ Research Institute of Petroleum Exploration and Development, PetroChina, Beijing 100083, China
}

\begin{abstract}
With the development of the Tazhong No.1 carbonate gas condensate reservoir in China, it has become more and more important to study the characteristics of gas condensate well deliverability. A single-well radial simulator for dual-permeability reservoirs was established to study the influences of fluid properties, permeability, and pressure drawdown on well deliverability with and without the capillary number effect. The simulation shows that well deliverability basically maintains its initial value and is not affected by the capillary number when the formation pressure is higher than dew-point pressure. However, well deliverability drops rapidly when the formation pressure is lower than dew-point pressure. Even if the condensate dropout is very low, well deliverability without the capillary number effect reduces to 50 percent of its initial value when reservoir pressure declines to 95 percent of dew-point pressure, but well deliverability is significantly improved if the capillary number effect exists. The capillary number effect is most significant when reservoir pressure is just lower than dew point pressure, then the effect decreases; the reduction of well deliverability is mainly caused by the reduction of gas relative permeability of the matrix system near the wellbore.
\end{abstract}

Key words: Carbonate reservoir, gas condensate, capillary number effect, well deliverability, dualporosity media

\section{Introduction}

Underground flow in gas condensate reservoirs usually exists as a single-phase gas flow under initial reservoir conditions when reservoir pressure is above the upper dew-point pressure. However, with the depletion of gas condensate reservoirs, a relatively high liquid saturation will build up in the vicinity of the wellbore when the bottomhole flowing pressure is below the dew-point pressure of the corresponding reservoir fluid. This is, known as condensate blocking (Boom et al, 1995). Condensate blocking will lead to a reduction in gas relative permeability, thus resulting in loss of well deliverability (Fussell, 1973). For example, in the Arun gas condensate reservoir, the largest liquid holdup of the retrograde condensate reservoir was about $1 \%$, but the well deliverability had been reduced nearly by half of the initial value as the reservoir pressure dropped down below dew-point pressure (Mott et al, 2000a). However, for some gas condensate wells, significant loss in well deliverability would not occur as reservoir pressure falls down below dewpoint pressure. This is due to the synthetic effect of low interfacial tension of gas condensate reservoirs and highvelocity fluid flow near the wellbore. This synthetic effect can be represented by the capillary number. In-depth research has been concentrated on conventional sandstone gas condensate reservoirs in this field, but few on carbonate gas condensate reservoirs (Asar and Handy, 1988; Ayyalasomayajula et al,

*Corresponding author. email: hyl@petrochina.com.cn

Received February 26, 2008
2005; Bengherbia and Tiab, 2002; Blom and Hagoort, 1998a; Fevang and Whitson, 1996; Tong et al, 2006). With the development of the Tazhong No.1 carbonate gas condensate reservoir in China, it has become increasingly important to investigate this type of gas condensate reservoir. The characteristics of well deliverability were investigated and the capillary number effect was also studied using a finegrid single-well radial compositional simulator for dualpermeability reservoirs.

\section{Capillary number effect model}

The gas velocity is relatively high near the wellbore in gas condensate reservoirs, and the gas phase can carry part of the condensate dropout to the surface. So oil saturation near the wellbore reduces with increasing gas relative permeability and weakening impairment by condensate blockage. This phenomenon can be expressed by the capillary number effect model. There are many definitions of capillary number so far, but the conventional definition is written as follows (Qin et al, 2004).

$$
N_{\text {cp }}=\frac{v_{\mathrm{g}} \mu_{\mathrm{g}}}{\sigma}
$$

where $N_{\mathrm{cp}}$ is the capillary number; $v_{\mathrm{g}}$ is the gas velocity in the direction of flow, $\mathrm{m} / \mathrm{s} ; \mu_{\mathrm{g}}$ is the gas viscosity, $\mathrm{mPa} \cdot \mathrm{s}$; and $\sigma$ is the gas-oil surface tension, $\mathrm{mN} / \mathrm{m}$

The capillary number model is mainly used to modify gas relative permeability (Blom and Hagoort, 1998b; Mott et al, 2000b), which can be expressed by the model developed by Whitson et al (1999). The gas relative permeability, when 
capillary number effect exists, can be described as follows:

$$
k_{\mathrm{rg}}=f_{\mathrm{I}} k_{\mathrm{rgI}}+\left(1-f_{\mathrm{I}}\right) k_{\mathrm{rgM}}
$$

where $k_{\mathrm{rg}}$ is the capillary number modified gas relative permeability; $k_{\mathrm{rg}}$ is the user-input immiscible, rock relative permeability at low capillary number; $k_{\mathrm{rgM}}$ is a straight-line miscible relative permeability at high capillary number value; $f_{\mathrm{I}}$ is a transition function depending on the gas capillary number, and can be given by:

$$
f_{\mathrm{I}}=\frac{1}{\left(\alpha N_{\mathrm{cg}}\right)^{n}+1}
$$

with

$$
\alpha=\frac{\alpha_{\mathrm{c}}^{0}}{\left(\frac{k_{\mathrm{rgM}}+k_{\mathrm{rgI}}}{2}\right) \sqrt{K \varphi}}
$$

where $K$ is the rock permeability, $10^{-3} \mu \mathrm{m}^{2} ; \varphi$ is the porosity; $\alpha_{\mathrm{c}}^{0}$ is a constant depending only on rock properties; $n$ is a coefficient; $\quad \alpha_{\mathrm{c}}^{\mathrm{o}}$ and $n$ are usually defaulted to be 0.65 and 10,000 , respectively.

\section{Simulation model and related description}

A compositional radial model was used to predict the single-well performance in dual-permeability carbonate gas condensate reservoirs and the capillary number effect was also taken into account. The grids of the model are built with $25(X$ direction $) \times 10(Y$ direction $) \times 2(Z$ direction $)=$ 500 nodes. The $Z$ direction grid is divided into two layers representing the matrix block system grid and the fracture system grid, respectively. One producer is located at the center of the model. In order to capture the flow performance near the wellbore, the grid is composed of logarithmically distributed radial nodes (Du et al, 2004). In other words, the cell block in the center (near the wellbore) is the finest and cell size increases with a logarithmic relationship. The innermost node size is only $0.36 \mathrm{~m}$, while that of the outermost node is $340 \mathrm{~m}$ wide. The thickness of the matrix layer is $30 \mathrm{~m}$ and its porosity is 0.1 ; while the thickness of the fracture layer is $10 \mathrm{~m}$, and its porosity is 0.01 . All the models have the same outside boundary of $1,300 \mathrm{~m}$. To reduce the complexity of three-phase interaction in the model, there is no aquifer in these models. Initial reservoir pressure is a little larger than the dew-point pressure of the reservoir fluid. Table 1 shows the components of each sample

\begin{tabular}{|c|c|c|c|c|c|c|c|c|c|c|c|c|c|c|c|}
\hline \multirow{2}{*}{$\begin{array}{l}\text { Well } \\
\text { name }\end{array}$} & \multicolumn{13}{|c|}{ Components, $\mathrm{mol} \%$} & \multirow{2}{*}{$\begin{array}{l}\text { Maximum liquid } \\
\text { yield in constant } \\
\text { volume depletion } \\
\text { (CVD), \% }\end{array}$} & \multirow{2}{*}{$\begin{array}{l}\text { Gas- } \\
\text { oil ratio } \\
\mathrm{m}^{3} / \mathrm{m}^{3}\end{array}$} \\
\hline & $\mathrm{C}_{1}$ & $\mathrm{C}_{2}$ & $\mathrm{C}_{3}$ & $i-\mathrm{C}_{4}$ & $n-\mathrm{C}_{4}$ & $i-\mathrm{C}_{5}$ & $n-\mathrm{C}_{5}$ & $\mathrm{C}_{6}$ & $\mathrm{C}_{7}$ & $\mathrm{C}_{8}$ & $\mathrm{C}_{9}$ & $\mathrm{C}_{10}$ & $\mathrm{C}_{11+}$ & & \\
\hline Well 1 & 86.34 & 1.42 & 0.56 & 0.21 & 0.36 & 0.23 & 0.25 & 0.50 & 0.58 & 0.65 & 0.43 & 0.34 & 1.58 & 12.51 & 2555 \\
\hline Well 2 & 88.42 & 2.21 & 0.72 & 0.20 & 0.35 & 0.15 & 0.17 & 0.25 & 0.21 & 0.33 & 0.29 & 0.27 & 1.36 & 8.34 & 4311 \\
\hline Well 3 & 93.84 & 0.91 & 0.19 & 0.03 & 0.07 & 0.03 & 0.04 & 0.05 & 0.07 & 0.10 & 0.09 & 0.09 & 0.64 & 1.14 & 5900 \\
\hline
\end{tabular}
and their properties.

Table 1 Components of each sample and their properties

Gas well deliverability at different reservoir pressures was then calculated. It is defined in terms of the productivity index, which is defined as the ratio of gas flow rate to pressure drop:

$$
J=\frac{Q_{\mathrm{g}}}{p_{\mathrm{r}}-p_{\mathrm{wf}}}
$$

where $J$ is the productivity index of gas wells, $\mathrm{m}^{3} /(\mathrm{d} \cdot \mathrm{MPa}) ; Q_{\mathrm{g}}$ is the gas flow rate, $\mathrm{m}^{3} / \mathrm{d} ; p_{\mathrm{r}}$ is the current reservoir pressure, $\mathrm{MPa}$; and $p_{\mathrm{wf}}$ is the bottomhole flowing pressure, MPa.

The concept of relative productivity index was proposed for the sake of comparison between different cases, and the relative productivity index is defined as follows:

$$
J_{\mathrm{r}}=\frac{J_{p_{\mathrm{r}}}}{J_{p_{\mathrm{i}}}}
$$

where $J_{\mathrm{r}}$ is the relative productivity index; $J_{p_{\mathrm{r}}}$ is the productivity index at reservoir pressure $p_{\mathrm{r}}, \mathrm{m}^{3} /(\mathrm{d} \cdot \mathrm{MPa})$; and $J_{p_{\mathrm{i}}}$ is the productivity index at initial reservoir pressure $p_{\mathrm{i}}$, $\mathrm{m}^{3} /(\mathrm{d} \cdot \mathrm{MPa})$.

A parameter $\Delta J_{\mathrm{r}}$ is defined to investigate the capillary number effect on the productivity index:

$$
\Delta J_{\mathrm{r}}=J_{\mathrm{r}}\left(N_{\mathrm{cp}}\right)-J_{\mathrm{r}}
$$

where $J_{\mathrm{r}}\left(N_{\mathrm{cp}}\right)$ is the relative productivity index with the capillary number effect.

In Eq. (7), $\Delta J_{\mathrm{r}}$ stands for the difference between relative productivity index with and without capillary number effect.

\section{Results and discussion}

\subsection{Effect of fluid characteristics}

For gas condensate reservoirs, the larger the initial gasoil ratio in the production well, the smaller the volume of retrograde condensed liquid, as shown in Table 1. Fig. 1 shows the reduction in relative productivity index for a well producing at different initial gas-oil ratios, where $p_{\mathrm{r}} / p_{\mathrm{D}}$ is the ratio of reservoir pressure to dew-point pressure. In the simulation, the initial reservoir pressure is slightly higher than the dew-point pressure of the gas, that means $p_{\mathrm{i}} / p_{\mathrm{D}}>1$. When $p_{\mathrm{r}} / p_{\mathrm{D}}>1$, the relative productivity index is approximately equal to unity, productivity index maintains at the initial value; when $p_{\mathrm{r}} / p_{\mathrm{D}}>1$, under the same conditions the smaller the well initial gas-oil ratio (GOR), the larger the maximum liquid yield, and the greater the well deliverability reduction. For Well 3, the maximum liquid yield in a CVD experiment 
is only $1.14 \%$, but the well deliverability decreases sharply with decreasing pressure at the initial GOR of $5,900 \mathrm{~m}^{3} / \mathrm{m}^{3}$, similar to the Arun gas condensate field (Mott et al, 2000a); and the well deliverability reduces by 50 percent when the reservoir pressure is 95 percent of dew-point pressure, then it decreases slowly with pressure and even has an upward trend under the effect of various factors. There is a little difference of productivity index between the reservoir fluids with initial GOR of $4,311 \mathrm{~m}^{3} / \mathrm{m}^{3}$ and that of $5,900 \mathrm{~m}^{3} / \mathrm{m}^{3}$, but both of them have a relatively large difference with that of $2,555 \mathrm{~m}^{3} /$ $\mathrm{m}^{3}$.

Figs. 1 and 2 indicate that the reduction in relative productivity index decreases significantly when the capillary number effect exists. Fig. 3 shows the capillary number effect on relative productivity index. The capillary number effect becomes important when reservoir pressure reaches dewpoint pressure, and the capillary number effect on relative productivity index was significant only when the reservoir pressure is slightly lower than the dew-point pressure of the corresponding gas. With decreasing reservoir pressure, the capillary number effect on relative productivity index drops gradually. Capillary number is related to fluid viscosity, fluid flow velocity and interfacial tension, the larger the initial GOR, the greater the capillary number effect. That is, the deliverability of gas wells can be improved further with the existence of the capillary number effect.

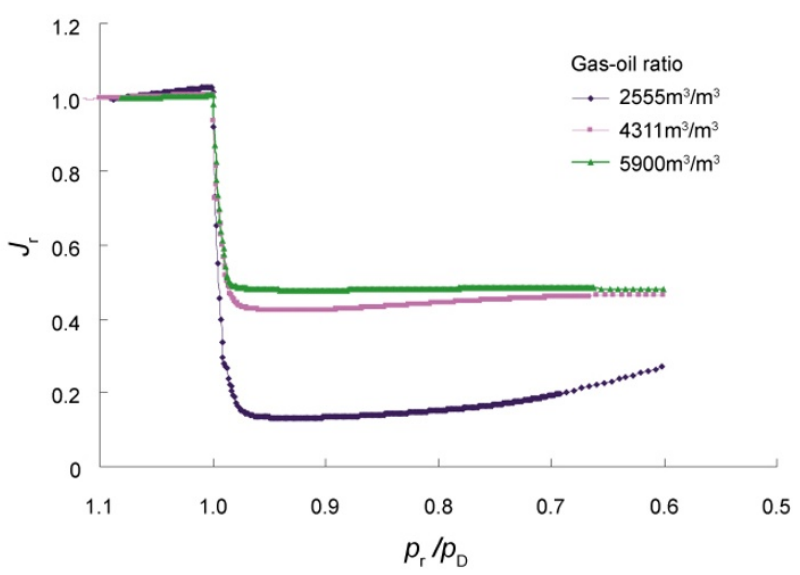

Fig. 1 Relative productivity index without capillary number effect

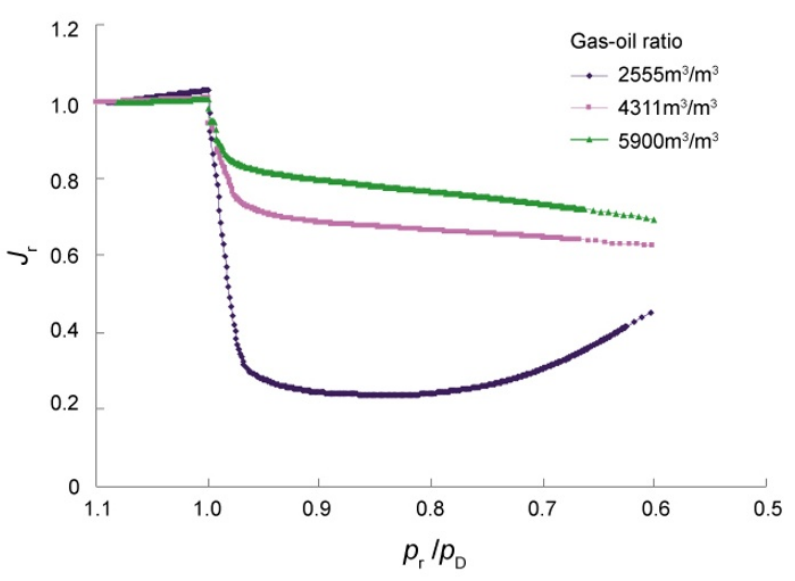

Fig. 2 Relative productivity index with capillary number effect

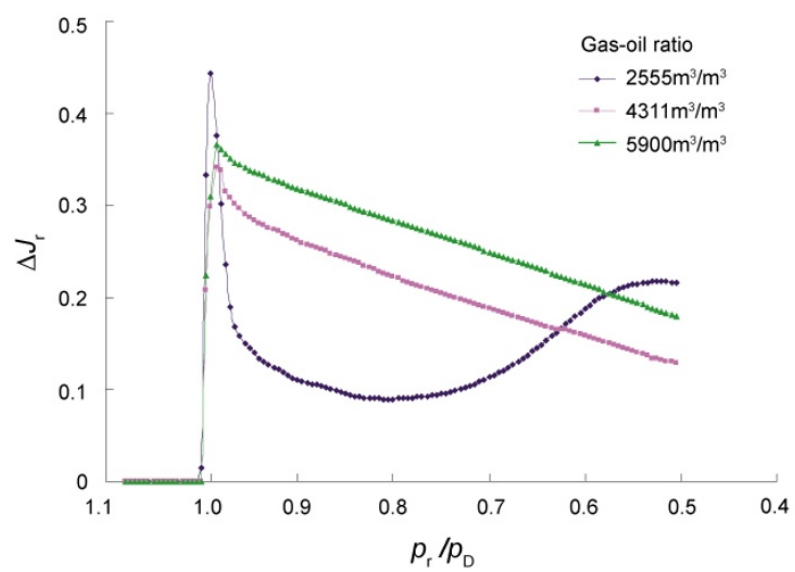

Fig. 3 The capillary number effect on relative productivity index

Additionally, Figs. 4 and 5 show the oil saturation and gas permeability distribution in the matrix block and fracture network in Well 1. Oil saturation in the matrix block near the wellbore is higher than that in the fracture network, which leads to a significant reduction in gas relative permeability of the matrix block. The gas relative permeability of the fracture network changes little because of lower oil saturation in the fracture network near the wellbore. Therefore, the deliverability loss of wells in carbonate gas condensate reservoirs is mainly caused by the reduction in gas relative permeability of the matrix block.

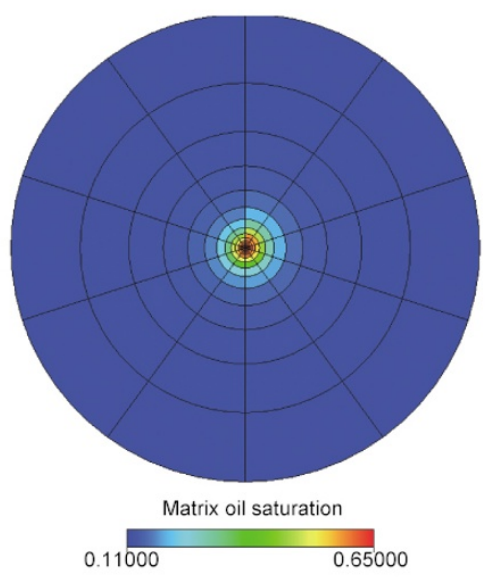

(a)

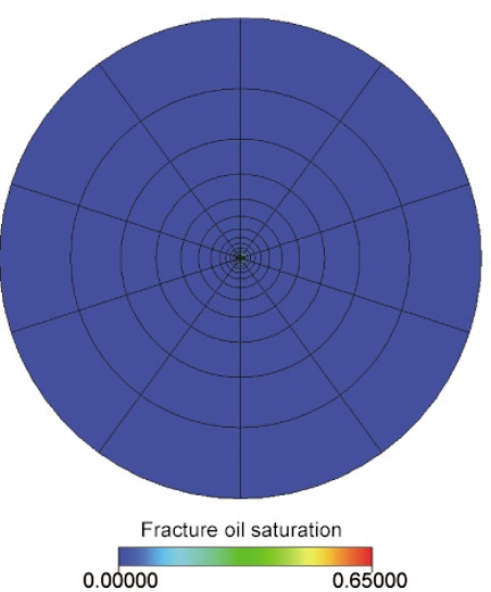

(b)

Fig. 4 Oil saturation distribution in the matrix block (a) and in the fracture system (b) at final simulation step (GOR is $2,555 \mathrm{~m}^{3} / \mathrm{m}^{3}$ ) 


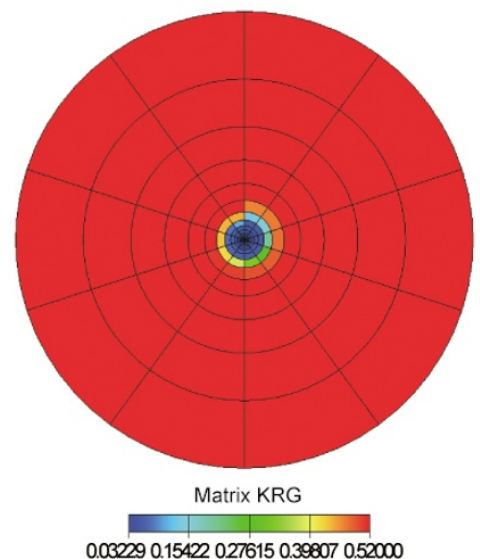

(a)

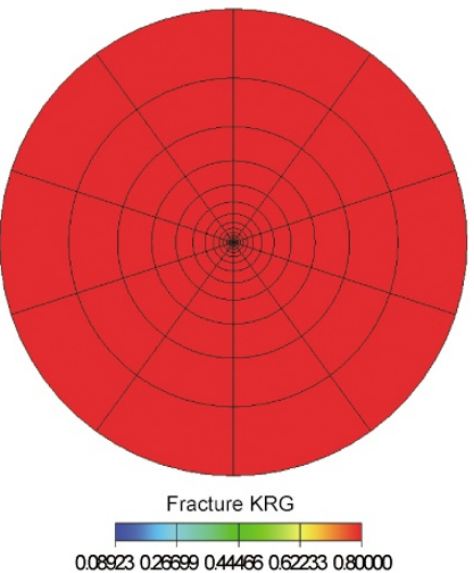

(b)

Fig. 5 Gas relative permeability distribution in the matrix block (a) and in the fracture system (b) at final simulation step (GOR is $2,555 \mathrm{~m}^{3} / \mathrm{m}^{3}$ )

\subsection{Effect of permeability}

The effect of permeability on well deliverability is more complicated because of severe heterogeneity of carbonate gas condensate reservoirs. Four scenarios with a ratio of fracture permeability to matrix permeability of 100:1 were established using PVT data of Well 2. The values of matrix permeability were set $1,5,10$ and $50 \mathrm{mD}$, respectively, and other parameters maintained the same value. Fig. 6 shows the relative productivity index curves, where $K_{\mathrm{m}}$ is the matrix permeability and $K_{\mathrm{f}}$ is the fracture permeability. It can be concluded that the smaller the matrix and fracture permeabilities, the larger loss the well deliverability. When the matrix permeability and fracture permeability increase to specific values, variation of permeability has slight influence on the relative permeability index.

Additionally, when the reservoir pressure is slightly below dew-point pressure, the reduction in relative productivity index of a low-permeability reservoir $\left(K_{\mathrm{m}}=1 \mathrm{mD}\right)$ is less than those of the others. The conclusion that the smaller the reservoir permeability, the smaller the productivity index loss, may be drawn only when $p_{\mathrm{r}} / p_{\mathrm{D}}$ is less than 0.9 . Table 2 presents oil saturation of different systems (matrix system and fracture system) at different simulation time-steps (the time-step when $p_{\mathrm{r}} / p_{\mathrm{D}}$ is equal to 0.957 and the time-step when simulation is terminated). The maximum oil saturation can reflect the impairment by condensate blocking and its effect on gas relative permeability. When $p_{\mathrm{r}} / p_{\mathrm{D}}$ is equal to 0.957 , the maximum oil saturation in the matrix block of $K_{\mathrm{m}}=1$ $\mathrm{mD}$ is lower than that of the others, while the maximum oil saturation of the fracture system is higher than those of the others. This is because the fracture system plays a dominant role in well production at the early stage, and the smaller the matrix permeability, the more significant the role of the fracture system and the smaller the impairment by condensate blocking. Therefore, the loss of relative productivity index of $K_{\mathrm{m}}=1 \mathrm{mD}$ reservoir is lower than those of the others. Whereas at the final simulation time, the maximum oil saturation of the matrix and the fracture systems of the low-permeability reservoir is larger than those of the others. That is, the gas relative permeability loss near the wellbore in this reservoir is the largest, which leads to the largest reduction in relative productivity index.

The capillary number effect on deliverability of gas wells was studied and shown in Fig. 7. It can be concluded that the smaller the permeabilities of the matrix block and the fracture system, the larger the capillary number effect on the well relative productivity index except for the low permeability carbonate gas condensate reservoirs, for which the capillary number effect is the smallest.

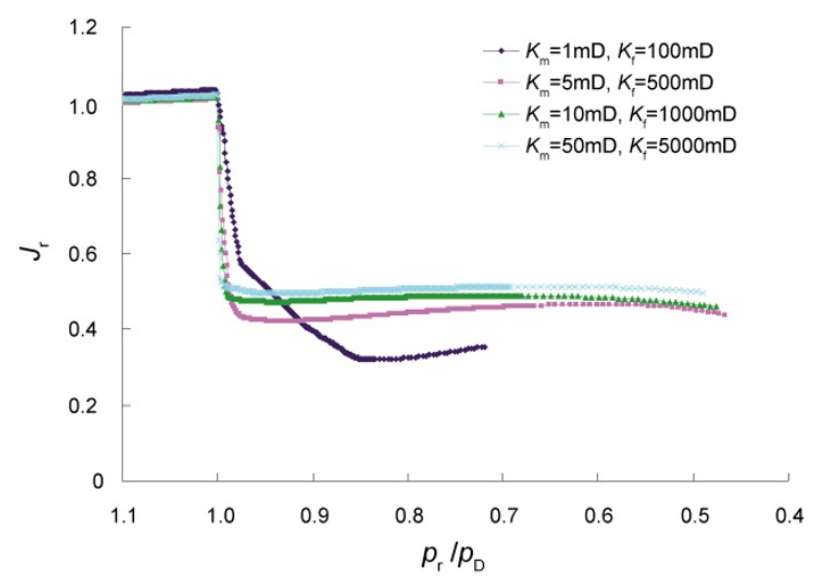

Fig. 6 Relative productivity index versus $p_{\mathrm{r}} / p_{\mathrm{D}}$ for different permeability scenarios

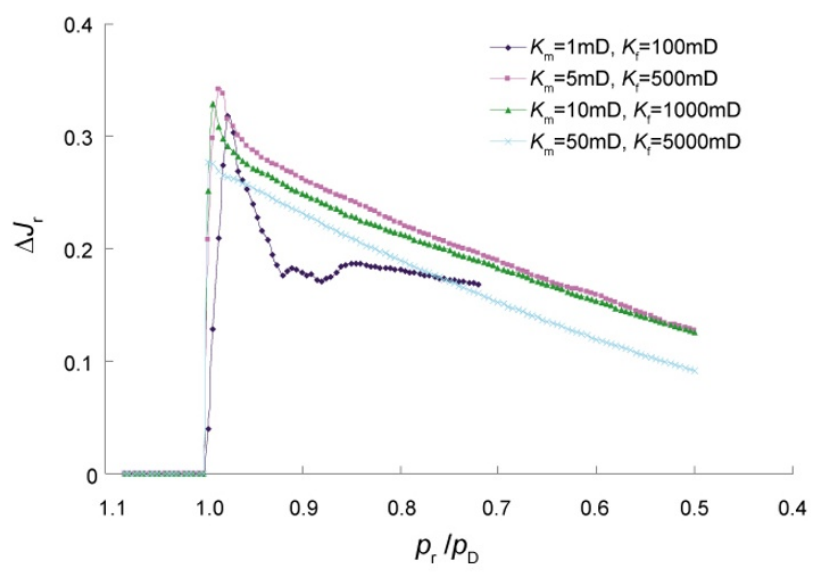

Fig. 7 The capillary number effect on relative productivity index at different permeabilities 
Table 2 Oil saturation comparison of different systems at different simulation times

\begin{tabular}{cccccc}
\hline \multirow{2}{*}{ System } & \multicolumn{2}{c}{$\begin{array}{c}\text { Maximum oil saturation } \\
\text { when } p_{\mathrm{r}} / p_{\mathrm{D}}=0.957, \%\end{array}$} & & \multicolumn{2}{c}{$\begin{array}{c}\text { Maximum oil saturation at final simulation } \\
\text { step, } \%\end{array}$} \\
\cline { 2 - 3 } & Matrix block & Fracture network & & Matrix block & Fracture network \\
\hline$K_{\mathrm{m}}=1 \mathrm{mD}, K_{\mathrm{f}}=100 \mathrm{mD}$ & 0.292 & 0.430 & & 0.555 & 0.501 \\
$K_{\mathrm{m}}=5 \mathrm{mD}, K_{\mathrm{f}}=500 \mathrm{mD}$ & 0.477 & 0.313 & & 0.465 & 0.134 \\
$K_{\mathrm{m}}=10 \mathrm{mD}, K_{\mathrm{f}}=1000 \mathrm{mD}$ & 0.438 & 0.179 & & 0.437 & 0.070 \\
$K_{\mathrm{m}}=50 \mathrm{mD}, K_{\mathrm{f}}=5000 \mathrm{mD}$ & 0.376 & 0.033 & & 0.379 & 0.0123 \\
\hline
\end{tabular}

\subsection{Effect of pressure drawdown}

Different gas production rates were set from PVT data of Well 2, to study the influence of pressure drawdown on well deliverability. The well gas production rate $\left(Q_{\mathrm{g}}\right)$ specified were $5 \times 10^{4}, 10 \times 10^{4}, 15 \times 10^{4}$, and $20 \times 10^{4} \mathrm{~m}^{3} / \mathrm{d}$, respectively. Greater gas production rate corresponded with higher pressure drawdown. Figs. 8 and 9 describe the influence of pressure drawdown on relative productivity index without or with the capillary number effect. Fig. 8 shows that the loss of well deliverability (i.e., relative productivity index) increases with increasing pressure drawdown rate. Figs. 9 and 10 indicate that the higher the pressure drawdown rate, the more significant the capillary number effect on relative productivity index.

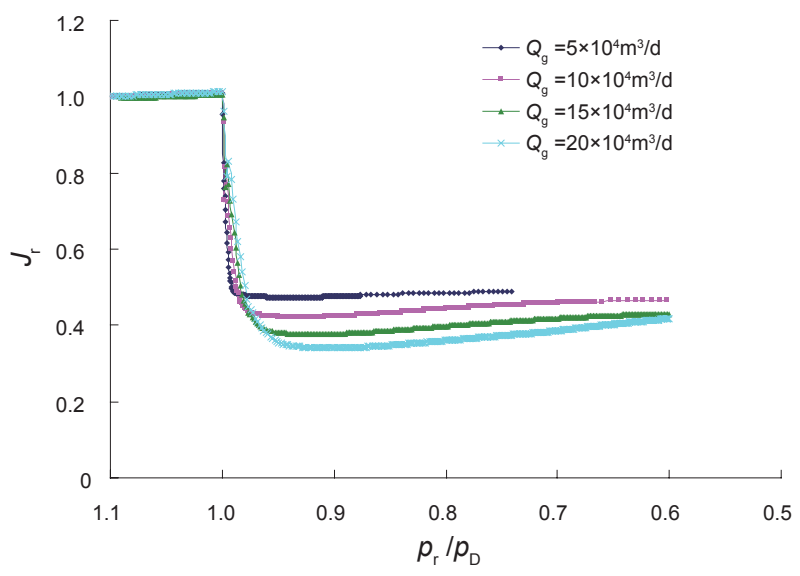

Fig. 8 Relative productivity index curves at different pressure drawdown rates without capillary number effect

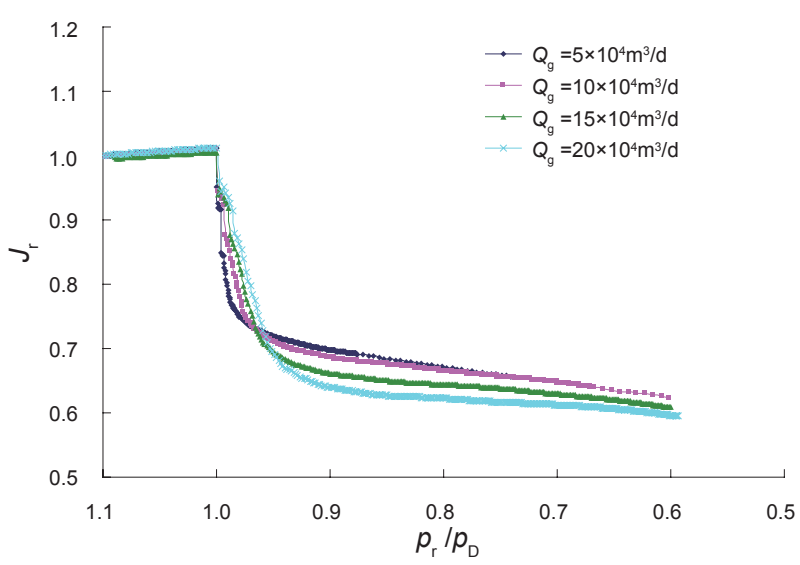

Fig. 9 Relative productivity index curves at different pressure drawdown rates when capillary number effect exists

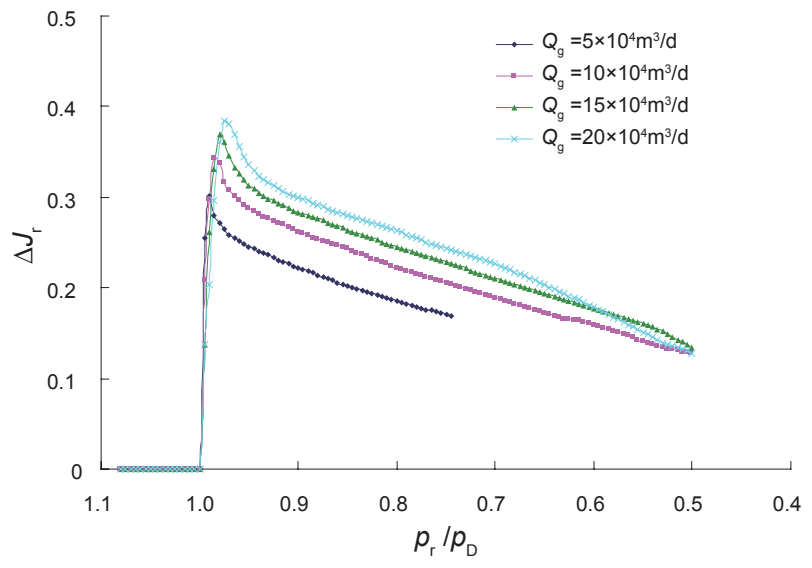

Fig. 10 The capillary number effect on relative productivity index at different pressure drawdown rates

\section{Conclusions}

1) The above-mentioned analysis indicates that condensate blockage has a significant effect on well deliverability and if the capillary number effect does not exist, the impairment by condensate blocking will be exaggerated.

2) Well deliverability will basically maintain its initial value when reservoir pressure is higher than dew-point pressure. However, it will drop rapidly just when reservoir pressure is smaller than dew-point pressure, even if the maximum liquid yield in a CVD experiment is only about one percent, well deliverability also decreases to 50 percent of its initial value at the early production phase, then it decreases little or even has an upward trend. The loss of well deliverability is mainly caused by the reduction of gas relative permeability of the matrix system.

3) Well deliverability can be significantly improved if the capillary number effect exists. The capillary number effect is insignificant when reservoir pressure is higher than dew-point pressure, and the capillary number effect is most significant just when the formation pressure is smaller than dew-point pressure, then the effect drops with the depletion of the reservoir.

4) Under the same conditions, the higher initial gasoil ratio (i.e., the larger maximum liquid yield in a CVD experiment) will lead to higher well deliverability loss. Also, the lower permeability of matrix and fracture system and the higher well gas production rate (i.e., the higher pressure drawdown rate) will result in significant reduction in well deliverability. 
5) The lower the permeability of matrix and fracture system, the larger the capillary number effect on well relative productivity index, except for low permeability carbonate gas condensate reservoirs. The higher the pressure drawdown, the more significant the capillary effect on the relative productivity index.

\section{Acknowledgments}

The authors would like to thank Project "973", a national fundamental research development program, for its financial support.

\section{References}

Asar H and Handy L L. Influence of interfacial tension on gas/oil relative permeability in a gas-condensate system. SPE Reservoir Engineering. 1988. 3(1): 257-264 (SPE 11740)

Ayyalasomayajula P, Silpngarmlers N and Kamath J. Well deliverability predictions for a low-permeability gas/condensate reservoir. SPE Annual Technical Conference and Exhibition, 9-12 October 2005, Dallas, Texas (SPE 95529)

Bengherbia $\mathrm{M}$ and Tiab D. Gas-condensate well performance using compositional simulator: a case study. SPE Gas Technology Symposium, 30 April-2 May 2002, Calgary, Alberta Canada (SPE 75531)

Blom S M P and Hagoort J. How to include the capillary number in gas condensate relative permeability functions? SPE Annual Technical Conference and Exhibition, 27-30 September 1998a, New Orleans, Louisiana (SPE 49268)

Blom S M P and Hagoort J. The combined effect of near-critical relative permeability and non-Darcy flow on well impairment by condensate drop out. SPE Reservoir Evaluation \& Engineering. 1998b. 1(5):
421-429 (SPE 51367)

Boom W, Wit K, Schulte A M, et al. Experimental evidence for improved condensate mobility at near wellbore conditions. SPE Annual Technical Conference and Exhibition, 22-25 October 1995, Dallas, Texas (SPE 30766)

$\mathrm{Du}$ Y, Guan L and Li D. Deliverability of wells in the gas condensate reservoir. 11th ADIPEC Abu Dhabi International Petroleum Exhibition \& Conference, 10-13 Octobers 2004, Abu Dhabi (SPE 88796)

Fevang $\varnothing$ and Whitson $\mathrm{C} \mathrm{H}$. Modeling gas condensate well deliverability. SPE Annual Technical Conference \& Exhibition, 22-25 October 1996, Dallas, Texas (SPE 30714)

Fussell D D. Single-well performance production for gas condensate reservoirs. JPT. 1973. 25(7): 860-870

Mott R E, Cable A S and Spearing M C. Measurements and simulation of inertial and high capillary number flow phenomena in gascondensate relative permeability. SPE Annual Technical Conference and Exhibition, 1-4 October 2000a, Dallas, Texas ( SPE 62932)

Mott R E, Cable A S and Spearing M C. Measurements of relative permeabilities for calculating gas-condensate well deliverability. SPE Reservoir Evaluation \& Engineering. 2000b. 3(6): 473-479 (SPE 68050)

Qin B, Li X F and Cheng S Q. Gas condensate two phase flow performance in porous media considering capillary number and nonDarcy effects. Petroleum Science. 2004. 1(3): 49-55

Tong M, Hu Y L, Li X F, et al. The influence of capillary number effect on inflow performance in condensate gas well. Xinjiang Petroleum Geology. 2006. 27(4): 194-196 (in Chinese)

Whitson C H, Fevang Ø and Saevareid A. Gas condensate relative permeability for well calculations. SPE Annual Technical Conference and Exhibition, 9-12 September 1999, Dallas, Texas (SPE 56476)

(Edited by Sun Yanhua) 